\title{
Transverse Facial Artery
}

National Cancer Institute

\section{Source}

National Cancer Institute. Transverse Facial Artery. NCI Thesaurus. Code C53025.

An artery arising from the superficial temporal artery that supplies the masseter muscle and corresponding skin as well as the parotid duct and parotid gland. 